\title{
Oxidation of Activated Phenols by Dioxygen Catalysed by the $\mathrm{H}_{5} \mathrm{PV}_{2} \mathrm{Mo10}_{40}$ Heteropolyanion
}

\author{
Manfred Lissel* and Helmut Jansen in de Wal \\ Fakultät fur Chemie,Universität Bielefeld \\ 4800 Bielefeld 1, FRG \\ Ronny Neumann* \\ Casali Institute of Applied Chemistry, Graduate School of Applied Science and Technology \\ The Hebrew University of Jerusalem, Jerusalem, Israel 91904
}

Key words: Heteropolyanions; Phenol Oxidation; Dioxygen

Abstract: The $\mathrm{H}_{5} \mathrm{PV}_{2} \mathrm{MO}_{10} \mathrm{O}_{40}$ heteropolyanion has been found to catalyse the highly selective aerobic oxidation of dialkylphenols to diphenoquinones and the oxidation of 2,3,5-trimethylphenol to the 2, 3,5trimethyl-1, 4-benzoquinone. The rate is highly dependent on the oxidation potential of the substrate and is proceeds by electron transfer from the phenol substrate to the heteropolyanion catalyst.

The ecological concerns surrounding the use of toxic and dangerous albeit very effective stoichiometric oxidants such as chromate and permangante etc. in the synthesis of fine chemicals has spurred an increasing amount of research into new catalytic systems which use clean and inexpensive primary oxidants especially dioxygen and hydrogen peroxide ${ }^{1}$. In this context there has been recent interest in the catalytic activity of heteropolyanions generally of the Keggin structure, $X_{M_{n}}^{\prime} M_{12-n} \mathrm{O}_{40}{ }^{y \cdot}\left(X=P, S i ; M=M o, W ; M^{\prime}=V ; n=0\right.$ 6). Thus, hydrogen peroxide has been used as oxidant in two phase catalytic reactions with the $\mathrm{XM}_{12} \mathrm{O}_{40} 0^{\mathrm{y}-}$ heteropolyanions and an non-symmetrical quaternary ammonium cation for the epoxidation of alkenes ${ }^{2}$, allyl alcohols ${ }^{3}$, and $\beta$-unsaturated acids ${ }^{4}$ and the oxidation of alcohols ${ }^{5}$, alkynes ${ }^{6}$, and phenol ${ }^{7}$. Some recent mechanistic studies ${ }^{8}$ have, however, additionally indicated that the original heteropolyanion is in fact only a catalytic percursor to a simplier catalytic peroxide species, $\mathrm{PO}_{4}\left[\mathrm{WO}\left(\mathrm{O}_{2}\right)_{2}\right]_{4}{ }^{3-}$ which had been previously identified ${ }^{9}$.

Entirely different reaction modes have been utilized for oxidations with dioxygen as primary oxidant in both photochemical ${ }^{10}$ and normal thermal systems. In the later case, $\mathrm{H}_{3+n} \mathrm{PV}_{n} \mathrm{Mo}_{12-n} \mathrm{O}_{40}$ (usually $\mathrm{n}=2$ ) has been used as a secondary oxidant in place of $\mathrm{CuCl}_{2}$ in Wacker type reactions ${ }^{11}$, in the oxidation of $\mathrm{HBr}^{12}$ and sulfides ${ }^{13}$, the oxidative cleavage of ketones ${ }^{14}$, and oxidative dehydrogenation of dienes ${ }^{15}$, alcohols and amines $^{16}$. These later reactions are pictured to proceed by the following generalized reaction scheme, eq 1 .

$$
\begin{aligned}
& \mathrm{SH}_{2}+\mathrm{H}_{5} \mathrm{PV}_{2}{ }_{2} \mathrm{Mo}_{10} \mathrm{O}_{40}(\mathrm{ox}) \longrightarrow \mathrm{S}+\mathrm{H}_{7} \mathrm{PV}^{\mathrm{iv}}{ }_{2} \mathrm{Mo}_{10} \mathrm{O}_{40}(\mathrm{red}) \\
& \mathrm{H}_{7} \mathrm{PV}^{\mathrm{iv}}{ }_{2} \mathrm{Mo}_{10} \mathrm{O}_{40} \text { (red) }+1 / 2 \mathrm{O}_{2} \longrightarrow \mathrm{H}_{5} \mathrm{PV}_{2}{ }_{2} \mathrm{Mo}_{10} \mathrm{O}_{40}(\text { ox })+\mathrm{H}_{2} \mathrm{O}
\end{aligned}
$$

In this manuscript we wish to report on the aerobic dehydrodimerization of dialkylphenols and the oxidation of 2, 3,5-trimethyl phenol to the vitamin $\mathrm{E}$ intermediate 2, 3, 5-trimethyl-1, 4-benzoquinone eq 2, 
(2)

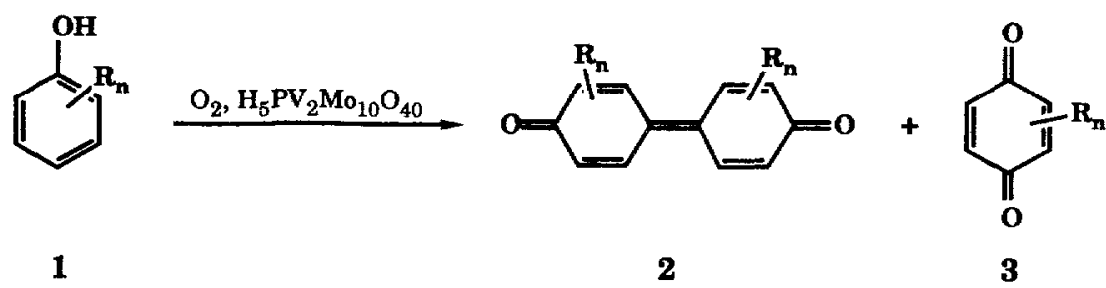

\section{Results and Discussion}

Reactions were carried out in a homogenous reaction phase at $60^{\circ} \mathrm{C}$ by dissolving $1 \mathrm{mmol}$ dialkylphenol, 1, and $0.02 \mathrm{mmol} \mathrm{H}_{5} \mathrm{PV}_{2} \mathrm{Mo}_{10} \mathrm{O}_{40}$ in $20 \mathrm{ml} \mathrm{n}$-hexanol under a oxygen (1 atm) atmosphere. After the reaction's completion the products were quantified either by isolation of the semicarbazone derivative ${ }^{17}$ or or by HPLC analysis ${ }^{18}$. From Table 1 showing both reaction yields and the oxidation potential of the phenol substrate, one can see that the sole product in the oxidation of the dialkylphenols is the dimeric diphenoquinone, 2. Furthermore, the yield is proportional to the oxidation potential of the phenol substrate. On the other hand, the more reactive 2,3,6 trimethylphenol exclusively yielded the monomeric benzoquinone, 3 . In a comparison of the results of the dialkylphenol oxidation with results obtained by two often used catalysts for this reaction, mainly the copper(II)chloride-amine complexe ${ }^{19}$ and the cobalt based compounds ${ }^{20}$ and also recently the manganese substituted heteropolyanion ${ }^{21}$, $\mathrm{SiMnW}_{11} \mathrm{O}_{39}{ }^{5-}$, one observes that the $\mathrm{H}_{5} \mathrm{PV}_{2} \mathrm{Mo}_{10} \mathrm{O}_{40}$ heteropolyanion catalyses formation of diphenoquinones whereas generally the cobalt and manganese systems yield benzoquinones as the major product along only minor amounts of diphenoquinones. Copper catalysts ${ }^{19,22}$ also have tended to yield diphenoquinones as the major product, however their activity is strongly dependent on reaction conditions, they are often less reactive and selective and yield a variety of additional side products including chlorinated phenols and polymeric ethers.

Table 1. Aerobic Oxidation of Alkylated Phenols Catalysed by the $\mathrm{H}_{5} \mathrm{PV}_{2} \mathrm{Mo}_{10} \mathrm{O}_{40}$ Heteropolyanion.

Substrate

2, 6-di-tert-butylphenol

2, 6-dimethylphenol

2, 5-dimethylphenol

3, 5-dimethylphenol

2, 3, 5-trimethylphenol
Product

$3,3^{\prime}, 5,5^{\prime}$-tetra-tert-

butyldiphenoquinone

3,3 ', 5, 5'-tetra-

methyldiphenoquinone

$2,2 ', 5,5^{\prime}$-tetra-

methyldiphenoquinone

$2,2^{\prime}, 6,6$ '-tetra-

methyldiphenoquinone

2, 3, 5-trimethyl-1,4-

benzoquinone
Conversion (yield) $\quad$ Oxidation Potential, $\mathrm{E}^{\circ}(\mathrm{V})$

$100(96)^{\mathrm{a}} \quad 0.68$

$80(80)$

0.76

$50(47)^{\mathrm{b}}$

0.82

$0(0)^{b}$

0.86

$75(73)^{c}$

0.69

Reaction Conditions: $1 \mathrm{mmol}$ substratc, $0.02 \mathrm{mmol} \mathrm{H} \mathrm{PV}_{2} \mathrm{Mo}_{10} \mathrm{O}_{40}, 20 \mathrm{ml}$-hexanol, $1 \mathrm{~atm}$ dioxygen, $60^{\circ} \mathrm{C}, 4 \mathrm{hr}$, conversions were computed by HPLC and yields given by isolated quantities. a) $25^{\circ} \mathrm{C} \mathrm{b}$ ) $90 \mathrm{hr}$ c) similar yields were found with ethanol, $\mathrm{n}$ propanol and n-butanol as solvents. 
In addition to the significant synthetic value of such inherently selective reactions we believe that inverse and high selectivity of the $\mathrm{H}_{5} \mathrm{PV}_{2} \mathrm{Mo}_{10} \mathrm{O}_{40}$ catalyst relative to the cobalt, manganese and copper systems along with the strong rate dependency on the oxidation potential of the organic substrate yields important insights into the possible mechanism of $\mathrm{H}_{5} \mathrm{PV}_{2} \mathrm{Mo}_{10} \mathrm{O}_{40}$ catalysed oxidations. Since it has been shown that the cobalt and manganese compounds catalyse the formation of benzoquinones by metal catalysed autoxidations ${ }^{23}$ the different selectivity found for $\mathrm{H}_{5} \mathrm{PV}_{2} \mathrm{Mo}_{10} \mathrm{O}_{40}$ would a priori indicate an entirely different mechanism. In order to test this hypothesis tetralin was autoxidised in a non-catalytic reaction to a mixture of $\alpha$-tetralone and $\alpha$-tetralin hydroperoxide, eq 3.<smiles>c1ccc2c(c1)CCCC2</smiles><smiles>O=C1CCc2ccccc2C1=O</smiles>

Thus, in a reaction performed at $70^{\circ} \mathrm{C}$ for $24 \mathrm{hr}$, with $1 \mathrm{~atm}$ dioxygen, tetralin yielded $25.2 \%$ hydroperoxide and $10.1 \%$ ketone. An identical reaction with $0.2 \mathrm{~mol} \% \mathrm{H}_{5} \mathrm{PV}_{2} \mathrm{Mo}_{10} \mathrm{O}_{40}$ showed no tetralin turnover indicating complete suppresion of autoxidation. The mode by which the $\mathrm{H}_{5} \mathrm{PV}_{2} \mathrm{Mo}_{10} \mathrm{O}_{40}$ catalyst inhibits autoxidation is unknown, but a plausible explanation is that thermally formed tetralin or tetralin peroxide radicals react very quickly with the heteropolyanion terminating the propogation of the radical chain reaction.

Another important facet of these phenol oxidations by $\mathrm{H}_{5} \mathrm{PV}_{2} \mathrm{Mo}_{10} \mathrm{O}_{40}$ heteropolyanion concerns the reaction's strong dependence on the oxidation potential of the phenol substrate. Measurement by cyclic voltammetry of the oxidation potential of the $\mathrm{H}_{5} \mathrm{PV}_{2} \mathrm{Mo}_{10} \mathrm{O}_{40}$ catalyst in a apolar solvent such as dichloromethane (the catalyst is dissolved in this phase by addition of tetraglyme) shows an oxidation potential of $0.81 \mathrm{~V}$. Therefore, phenols with a oxidation potential less than that of the catalyst will react while those with a greater potential will be inert and one may conclude that the thermodynamics of the interaction hetween the organic phenol and the $\mathrm{H}_{5} \mathrm{PV}_{2} \mathrm{Mo}_{10} \mathrm{O}_{40}$ catalyst, eq 4, will determine whether the reaction proceeds.

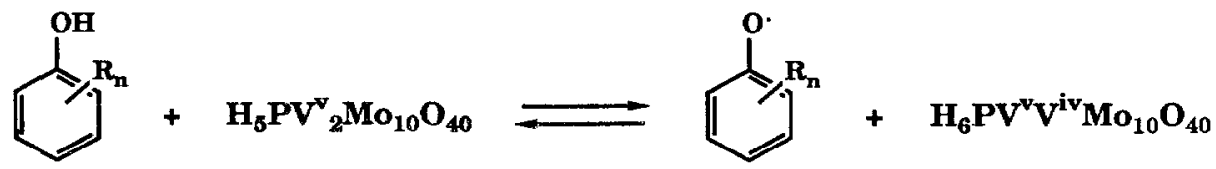

This thermodynamic control by the first electron transfer step of the reaction is significant keeping in mind that the reaction with any phenol would be thermodynamically favorable in its entirity due to the large free energy of reaction gained in the conversion of dioxygen to water. The electron transfer can be monitored visibly or by UVvis spectroscopy whereby reactive compounds interact by with $\mathrm{H}_{5} \mathrm{PV}_{2} \mathrm{Mo}_{10} \mathrm{O}_{40}$ forming reduced heteropolyanion blue compounds. An interaction with a one electron donor as previously found for compounds such as limonene ${ }^{15}$ and in this case with phenols gives a green reduced heteropolyanion and a phenoxy radical. It is not clear whether these species are free radicals or whether they are phenol-heteropolyanion intermediates. The fact that phenoxy radicals thus formed may either combine to yield the diphenoquinone as found for the dialkylphenols or insert dioxygen as found for trimethylphenol resulting in the benzoquinone product, suggests that the nature of the phenol - catalyst interaction and phenoxy radical is also a function of the oxidation potential.

One may conclude by stating that the $\mathrm{H}_{5} \mathrm{PV}_{2} \mathrm{Mo}_{10} \mathrm{O}_{40}$ heteropolyanion is a highly selective catalyst for the aerobic oxidation of polyalkylphenols with a basic product profile similar to copper catalysed reactions, however with higher reactivities, selectivities and fewer by products. The oxidation potential of the phenol 
substrate is decisive in determining whether the reaction will take place and possibly also the nature of the product. At present further research efforts are being made to develop new synthetic applications and to study the mechanistic aspects of $\mathrm{H}_{5} \mathrm{PV}_{2} \mathrm{Mo}_{10} \mathrm{O}_{40}$ heteropolyanion catalysed aerobic oxidations.

\section{References and Notes}

1. Sheldon, R.A. Studies in Surface Science and Catalysis 55; Centi, G.; Trifiro, F. Eds.; Elsevier; Amsterdam, 1990, pp 1-32.

2. Ishii, Y.; Yamawaki, K.; Yamada, H.; Yoshida, T.; Ogawa, M. J. Org. Chem., 1988, 53, 3587.

3. Matoba, Y.; Inoue, H.; Akagi, J.; Okabayashi, T.; Ishii, Y.; Ogawa, M. Synth. Commun., 1984, 14, 865 .

4. Oguchi, T.; Sakata, Y.; Takeuchi.; Kaneda.; Ishii, Y.; Ogawa, M. Chem. Letters, 1989, 2053.

5. Yamawaki, K.; Yoshida, T.; Nishihara, H.; Ishii, Y.; Ogawa, M. Synth. Commun., 1986, 16, 537. Daumas, M.; Vo-Quang, Y.; Vo-Quang, L.; Le Goffic, F. Synthesis, 1989, 64.

6. $\quad$ Ballistreri, F.P.; Failla, S.; Spina, E.; Tomaselli, G.A. J. Org. Chem., 1989, 54, 947.

7. Shimuzu, M.; Takehira, K.; Hayakawa, T.; Orita, H. Jpn. Kokai Tokkyo, Koho Jp 01,238,552.

8. Aubry, C.; Chottard, G.; Platzer, N.; Brégeault, J.-M.; Chauveau, F.; Huet, C.; Ledon, H. $4^{\text {th }}$ International Symposium on Activation of Dioxygen and Catalytic Oxidation, September 1990.

9. Venturello, C.; Aloiso, R.D.; Bart, J.C.;Ricci, M. J. Mol. Cat., 1985, 32, 107.

10. Fox, M.A.; Cardona, R.; Gaillard, E. J. Am. Chem. Soc., 1987, 109, 6347.

Renneke, R.F.; Hill, C.L. J. Am. Chem. Soc., 1986, 108, 3528.

11. Kozhevnikov, I.V.; Matveev, K.I. Russ. Chem. Rev., 1978, 47, 1231.

12. Neumann, R.; Assael, I. J. Chem. Soc., Chem. Commun., 1988, 1285.

13. Kozhevnikov, I.V.; Simanga, V.I.; Varnakova, G.V.; Matveev, K.I. Kinet. Katal., 1979, $20,506$.

14. El Ali, B.: Brégeault, J.-M.; Martin, J.; Martin, C. New J. Chem., 1989, 13, 173.

El Ali, B.: Brégeault, J.-M.; Mercier, J.; Martin, J.; Martin, C.; Convert, O. J. Chem. Soc., Chem. Commun., 1989, 825.

15. Neumann, R.; Lissel, M. J. Org. Chem., 1989, 54, 4607.

16. Neumann, R.; Levin, M. J. Org. Chem., 1991, 56, 5707.

17. The solution was diluted with $5 \mathrm{ml}$ methanol, $1 \mathrm{gm}$ semicarbazone $\mathrm{HCl}$ in $5 \mathrm{ml}$ water was added and the mixture was shortly heated. The semicarbazone derivative was filtered and dried.

18. HPLC analyses were performed using a Nucleosil $100-3$ column with $10 \%$ dichloromethane in $n-$ hexanol as eluent at a flow rate of $1 \mathrm{ml} / \mathrm{min}$.

19. Takehira, K.; Shimuzu, M.; Watanabe, Y.; Orita, H.; Hayakawa, T. Tetrahedron Lett., 1989, $30,6691$. Vierson, F.J.; Challa, G.; Reedijk, J. Rec. Trav. Chim. Pays-Bas, 1990, 109, 97.

Hay, A.S.; Blanchard, H.S.; Endres, G.F.; Eustance, J.W. J. Am. Chem. Soc., 1959, 81, 6335.

Finkbeiner, H.; Hay, A.S.; Blanchard, H.S.; Endres, G.F. J. Org. Chem., 1966, 31, 549.

20. Ganeshpure, P.A.; Sudalai, A.; Satish, S. Tetrahedron Lett., 1989, 30, 5929.

Sasaki, I.; Pujol, D.; Gaudemer, A.; Thuéry, P.; Claude, R.; Zarembowitch, J. New J. Chem., 1989, $13,843$.

21. Katsoulis, D.E.; Pope, M.T. J, Chem. Soc., Dalton Trans. 1989, 1483.

22. The similarity of $\mathrm{CuCl}_{2}$ catalysed oxidations with that of $\mathrm{H}_{5} \mathrm{PV}_{2} \mathrm{Mo}_{10} \mathrm{O}_{40}$ oxidations was first noted in Wacker type reactions (ref 11) with the significant advantage of the latter being that the chlorinated side products are eliminated.

23. Sheldon, R.A.; Kochi, J.K. Metal-Catalysed Oxidations of Organic Compounds; Academic Press: New York. 1981. 